\title{
THE COMMUNAL AND RENEWED KIBBUTZ: IDEOLOGY, MANAGEMENT AND INSTITUTIONAL CHANGE
}

\author{
Michael SOFER ${ }^{1} \bullet$ Ephraim S. GROSSMAN ${ }^{2} \bullet$ David GROSSMAN $^{1}$ \\ Bar-Ilan University \\ ${ }^{1}$ Department of Geography and Environment $\bullet{ }^{2}$ The Interdisciplinary Department of Social Sciences \\ Ramat-Gan, Israel 52900 \\ soferm1@biu.ac.il•grossme1@biu.ac.il•david.grossman@biu.ac.il
}

\begin{abstract}
This study considers the roles of management and ideology in modifying the sustainability of communal systems. We approached this issue by discussing the major forces that shaped the planned kibbutz and the recent processes that have brought about its current transformation. Using a questionnaire-based survey we tried to reveal the relative importance that the members attach to traditional kibbutz values and their perception of the tension between the original ideology and the management strategies that have been imposed on the communal society by both external and internal forces. The findings indicate that pragmatism tends to prevail over ideology and communality has difficulty in functioning effectively in a highly complex and changing world. It points to the weakening of the communal system and to growing disengagement from principles of equality. However, the process and project of reshaping the kibbutz is ongoing.
\end{abstract}

Key-words: Israel, kibbutz, communality, renewed kibbutz, organizational change, restructuring.

\section{Introduction}

The kibbutz (pl. kibbutzim) is one of the forms of planned rural settlement in Israel. Since its inception more than one hundred years ago (the first kibbutz, Degania, was established in 1909), its ideas and principles have been continually debated by its members and its institutional structures and values have been re-evaluated. As an economic and social organization, it was frequently required to adjust to the external environment in which it was operating, even though its principles tended to place the kibbutz on a certain "pedestal" of exclusivity until the mid-1980s. The study of the kibbutz experience can throw light on the role of proper planning and management for the sustainability of communal systems. The idealism versus pragmatism debate is not new, but recent processes have drastically altered the possible solutions.

The first part of this paper consists of a discussion of the major forces and processes of change in the rural space in Israel and in the kibbutz based on an examination of the relevant literature. The second part is based almost exclusively on the findings derived from closed questionnaires that were distributed among members, managers and community 
leaders of two kibbutzim. The aim was to identify the relative role of the pragmatic versus the ideology variables, as viewed by the kibbutz members, as well as to consider the roles of management and ideology in modifying the sustainability of communal systems.

\section{Common property}

In this article the term communal applies to economically-based rural systems that were concerned, in their formative stage, with extracting industries (particularly agriculture), even if they turned in time to secondary and tertiary activities in order to earn a livelihood. We are concerned, thus, with common property resources and their management.

Stevenson (1991, p. 46) defined the term common property as "a form of resource management in which a well-delineated group of [...] users participate in extraction or use of a jointly held [resource] according to explicitly or implicitly understood rules". Significantly, the word management is here part of the basic definition. There is a large variety of other terms, ideas and cultural variations that govern each of the communal institutions, whether its rules are officially sanctioned or not. The implication is that rules have to be enforced, even though their application may be flexible (Blomley 2005; Runge 1992).

Many communal groups had difficulty in successfully managing themselves. This probably accounts for the short-lived existence of many of them. The number of communes that were founded in the United States between the beginning of the nineteenth century and 1939 was impressive: a total of 236. But most of them survived for a short period of time (Oved 1993). Communal systems which survived longer, even for several centuries, were mostly those that played vital roles like provision of food security by regulating land use or overcoming the unpredictable vagaries of climate and human-generated uncertainties (Netting 1993). This has been confirmed in the Middle East and in other parts of the world (Grossman and Kark 2004). The specific constraints differ widely, but the common denominator of long-living communal systems was their practical functioning, such as pooling resources, coordinating seasonal village activities, or unexpected security issues (Andelson 1991; Morin 1996; Sofer 2009).

The survival of communal systems may be hampered by the need to change rules because of gradual or sudden alterations of social, political, or economic causes, or because of a series of events that occur at close intervals and have a strong impact on the existing organizations and their management effectiveness. Other factors that influence prospects for communal sustainability are the nature of the rules, the sanctions used for imposing the rules, and the various economic categories to which the communal holdings are applied (Ostrum 1990, 1999). Also effective leadership, insistence on equity and, most importantly, an uncompromised avoidance of 'free riding' practices (Oakerson 1992). If the latter becomes a norm, the very essence of communality is undermined. The last point is a rephrasing of the core-message of the well-known "Tragedy of the Commons" article (Hardin 1968). 


\section{Recent changes in the rural space}

Rural areas in developed economies have been experiencing significant and multi-dimensional changes in recent years due to both ongoing long-term economic, socio-demographic and environmental processes, and various external factors. Among the outcomes there is the need to restructure land and labor, which is reflected in the decreased ability to farm and manage land resources, and in the growing number of rural residents adopting non-agricultural occupations (Sofer and Applebaum 2006). A second outcome is a notable change of the socio-demographic composition of the subject population, where out-migration has led to a distorted age structure especially in peripheral areas (Beteille 1994; Robinson 2004). A third one is urban encroachment and penetration of the rural space by in-migrants and external activities. This results in a permanent loss of agricultural land to housing, industry and infrastructure projects, and contributes to the gradual decline of the open green space (Edelman et al. 1999). A fourth result is that rural social structure is undergoing basic modifications. Among the conspicuous ones is that the degree of cooperation is reduced, as reflected in social and economic terms (Hogeland 2004). These changes have brought to the forefront a perception that rural landscapes possess a range of commodity and non-commodity use values simultaneously, and thus should not be linked to the traditional view as being solely agricultural, but rather as multifunctional space (McCarthy 2005; Woods 2010).

These processes have been operating in Israel where agriculture was the mainstay of rural settlement for many decades. However, in recent years changes and adjustments have been made in order to retain a competitive edge on the local and international markets. The importance of agriculture to the state economy has declined. The contribution of agriculture to the GDP in 2012 was a mere 1.7 percent, compared with about 4.8 percent in 1980 (CBS 2013). At the same time, the sector's productivity has significantly increased, in terms of both output per unit of labour and output per unit of capital. However, there have been other trends in the other sector's indicators: worsening terms of trade, fluctuation in income derived from agricultural production, and decline in the number of self-employed farmers (Ministry of Agriculture 2011). The outcome has been an increase in the employment share of other sectors. The major increase in rural employment has been in the public services followed by commerce and tourism.

The changes have particularly affected the cooperative farming communities of which the kibbutz is a major pillar. The resulting restructuring process of both rural space and rural communities has led to the emergence of new strategies of survival, such as farm diversification and pluriactivity, developed to cope with changing conditions. The ensuing effects include industrialisation of the rural space, a heightened penetration of commercial and service-sector businesses into villages, and an increase in commuting to employment hubs in the urban centres (Sofer and Applebaum 2009).

A major trigger to these changes was the economic crisis in the mid-1980s which resulted from government efforts to curb run-away inflation by means of a steep interest hike (Pauker 2011). Unlike former policies (a policy termed 'neo-corporatism' by Schwartz 1995), the government refused to bail out indebted settlements, including the kibbutzim, the most seriously affected sector. The eventual rehabilitation process structured for enabling a stronger economic base for the kibbutzim included a policy which allowed the re-zoning of farmland for non-farm uses, curtailing the political and economic power of 
the cooperative movements and organizations, and allowing the development of expansion residential projects in the cooperative settlements. These measures accelerated the modification of the rural space and the transformation of the rural communities (Lapidot et al. 2000, 2006; Schwartz 1999).

\section{The ideological tenets of the kibbutz: early evolution and modifications}

\section{The principles}

The kibbutz, a planned cooperative settlement, adopted mainly during the first two generations of its existence (until about 1970), several variations of socialist ideologies which became part of ideological movements, which differed from each other by their relative strictness on a communalism-liberalism continuum. A major principle of the kibbutz ideology was economic and social equality among its members. The kibbutz economy was originally based on the sharing of all economic activities, i.e., production, external commerce and consumption. All means of production belonged to the community and its members. Management of economic activities was in the hands of the kibbutz members and they were expected to provide all the labour. Income from all sources went into a common purse. The kibbutz assumed responsibility for all the needs of its members, and there was no link between type and amount of work and monetary remuneration.

Even though adjustments were not new to the kibbutz system from its very beginning, the depth of the mid-1980s changes were unprecedented. The economic crisis brought to the surface dormant pressures to alter the system, to liberalize its economic environment and to allocate some degree of personal choice to the members. Inevitably, this led to individualization and to eventual privatisation of many kibbutzim (Gal 2011).

\section{Spheres and forms of change}

There are 270 kibbutz type settlements in Israel with about 150,000 residents, which make up about 1.9 percent of the state's population (CBS 2013). The dormant pressure to change evolved primarily from the widening gap between the economic and social reality and the kibbutz' original values. There is an ongoing debate about the degree of deviation from the previous norms that the new systems have generated. Some argue that their cumulative effect amounted to a revolution (Ravid 1994; Rosolio 1999), while others insist that they have only begun to operate under market principles and structured hierarchical mechanisms (Ben-Rafael 1997; Rosner and Getz 1994). But there is no doubt that the changes are spreading and an increasing number of kibbutzim are adopting them, even though there is a wide range of variation (Ben-Rafael 2003; Lapidot et al. 2006; Mort and Brenner 2003; Palgi and Reinharz 2011; Rosolio 1999; Russell et al. 2006).

The kibbutz existing types should be placed on a spectrum, rather than considered as dichotomies, because each kibbutz decides on which and how many innovations to adopt (Russell et al. 2006). However, the kibbutz movement itself recognizes a four-tier system of the types (termed 'livelihood modes'): (1) collective, (2) collective minus, (3) compounded, (4) security net (renewed) (Palgi and Orchan 2005). Only about one third of the kibbutzim are now considered as fully collective, but the dynamic change process does not operate in favor of this type. Moreover, the government has adopted Ben-Rafael's (2003) committee's Report to recognize the existence of a renewed form of the kibbutz. 
It is possible to categorize the main changes into a number of spheres. In the sphere of production there has been a separation between the production units, particularly non-agricultural ones, from the community, and in an increasing number of cases, the building of partnerships with external sources of capital; allocating responsibility to each economic unit to provide profits (termed 'profit centers') i.e. decentralization of authority; establishing a 'managerial class' in order to run enterprises according to the competitive markets rules; introducing boards of directors that include even non-members (Topel 2011); encouraging, to an increasing extent, the responsibility of members to choose jobs and to raise income and, significantly, ignoring the original principle of self-labour and regarding hired labour as a vital necessity (Gets 1998; Helman 1994; Gal 2011). Additional change is turning more widely to external markets by selling services to individuals and firms located outside the kibbutz. Another important trend is the formation of regional affiliations for common projects, which replace, to some extent, the weakened ideological-based roof-organizations. An expression of this tendency is the strengthening position of the Regional Council at the expense of the kibbutz secretariats and the internal institutions (Bijaui 2005; Degani 2006).

In the sphere of consumption there has been a major transfer of responsibility from the community - the collective purse - to the individual and the family unit. A personal budget was introduced along with a growing degree of spending freedom. Members are charged for previously free resources and services such as meals in the dining hall, the use of the collective's cars, electricity and other utilities (Getz 1998; Helman 1994; Pavin 2011).

\section{The business sector: Re-organization and management changes}

There have been many changes in the management and the economic organizational structure of the kibbutz, and in various economic institutions. The increasing complexity of management and decision making is placed in the hands of a fewer number of authorized persons who have the proper expertise. The elected executive officers (secretaries; now renamed community managers) were gradually granted wider authority, and replaced various committees formerly engaged in economic and social matters. The original obligatory rotation of managers was abolished. The formation of an elite class was, in fact, not totally new, because the need for electing appropriate leadership never allowed the rotation of such jobs among the entire membership (Topel 2011).

The decision of some kibbutzim to separate business operations from the community was a fundamental change. This was accompanied by appointing a dual decision-making system and by depriving the community of sharing the profits or the dividends that had formerly been allocated to them (Russell et al. 2006; Topel and Ben-Rafael 2006). Members are increasingly allowed to establish their own enterprises, such as workshops, consulting services, or retail activities, while the community received a share of the profits. In addition, the number of members working on the outside, mostly in urban localities, greatly increased. The changing business environment required a re-shuffling of the former economy and of opening it up to private investment. Numerous kibbutz industries have been merged with other kibbutzim or with private firms. Listing with the Israeli or foreign Stock Exchanges is now a standard procedure (Cohen 2006).

The changes have affected the whole employment structure. Most kibbutzim gave up the past dominant principle of self-employment and encouraging volunteers to work 
in their different sectors, instead some of them even hired foreign agricultural labour in recent years (Storm 2011). About 30 percent of the labour force, according to our findings (information provided by managers during the field work) consists of hired non-kibbutz workers, employed in farming, services and other blue-collar jobs. Industrial production is partly out-sourced and many kibbutzim have established offshore branches taking advantage of access to low cost labour markets. Many kibbutzim have branches of their industrial companies in foreign countries in order to facilitate contacts with their customers. They have become, in short, more capitalistic and increasingly globalised (KIA internet site).

This 'profit center' practice contributes to the stability of the kibbutz as a whole and facilitates supervision of members and non-members. The former were previously assumed either self-disciplined or sensitive to peer criticism. The new managers have a better chance than the former branch-heads to spot 'free-riders' or negligent behaviour and can use adequate sanctions, if necessary.

The differences between the old and the new systems has given rise to heightened tensions that have led to growing social deprivation and increased economic inequality. The profit-motivated management has been known to discharge former member - "employees". Unemployment was previously unknown, but is now an emergent issue.

\section{The changing perception of consumption}

The outcome of the transformation process has been most pronounced in the provision of services to members. The kibbutz was the only Israeli cooperative settlement that had insisted on including consumption in its rules. This is gradually disappearing, but the erosion process had been brewing for a long time. Budget allocations have gradually attained the form of wages. The idea that people could be taught to refrain from capitalist accumulation failed to materialize. Examples of this sobering disillusionment have been abundant since the early 1990s (Ben-Rafael 1997; Discussions Team 1991, 1992; Pavin 2011). The erosion of past bans on private ownership accelerated during the 1990s and the privatized drive progressively included an increasing number of consumption items, including even family cars. The right to own the home apartment has recently become a major issue whose implementation has become widely popular, but its realization has been slow or delayed because of several legal issues.

The gradual erosion of the communal consumption principle trend also added to the community's control over consumption. But the privatization process has not necessarily been in the individual's favour. Privatizing utilities such as water supply, electricity or line telephones was clearly against the interests of most members, who were accustomed to consume them freely. The significance of this transition is covered in the next chapter and will focus, among other topics, on some of these cases from the members' perspective. 


\section{Response to changes: The members' point of view}

\section{The survey: Purpose, methods and data}

The purpose of the survey presented in this section is to assess the members' views about the values and management practices more than two decades after the mid-1980s crisis. The central research question is to what extent is there still an inter-relationship between these two; i.e., are the traditional values still adhered to by the kibbutz member, and how these stands are expressed in practice by their evaluation of the manner by which their kibbutz's economy is currently run?

The questionnaire was originally distributed among a random sample of 15-30 percent of the members of four kibbutzim stratified by age groups. Because of the relatively low response from two kibbutzim, we decided to include in the present paper only the two that had the largest response levels (31 and 24 households' questionnaires respectively). One is located in the Tel-Aviv rural-urban fringe and the other in the northern Sharon plain. Both are near the main economic core of Israel. The total number of valid returned questionnaires from the two kibbutzim that we retained was 55, we feel that they still enable us receive some valuable tendencies related to the changes in the kibbutz system.

The questions were grouped into several themes (sets of variables) which were analyzed by Pearson correlations. The sets referred to the main groups of variables that we posed in our research:

- On the principle of full equality

- On traditional (classic) values of the kibbutz

- On traditional and innovative management practices

- On traditional and new consumption practices and privatizing service provision.

These sets contained 65 individual variables (a few of them were eliminated when we realized that their contribution to our research was minimal). The answers were tabulated and analyzed, mostly by using the Communality Index (see below) and by calculating the intra-set variance. In a few cases, the intra-set correlation coefficients were also calculated and ranked by the degree of their conformity to the basic kibbutz tenets and to the respondents' adherence to traditional management practices.

We started the questionnaires by asking the responders what their perception of the impact of the overall change process was (on him and on various other bodies). The members' choices on this question and on a few other sets were tabulated, but most other questions (excluding the answer "do not know"), in regard to the communality tenets or the management, were graded on a ' 0 ' to '100' scale, that we called Communality Index (CI), by reversing the variables (questions) that were negatively phrased, i.e., we disregarded the original wording of the printed question and presented the responses in a uniform manner (Box 1).

Box 1. The method of grading positively and negatively phrased questions

\begin{tabular}{|l|c|c|c|}
\hline \multicolumn{1}{|c|}{ Choice } & Cl & Positively Phrased & Negatively Phrased \\
\hline Fully disagree & 0 & 1 & 4 \\
Partly disagree & 33.3 & 2 & 3 \\
Partly agree & 66.7 & 3 & 2 \\
Fully agree & 100 & 4 & 1 \\
\hline
\end{tabular}


For the positive phrase the $\mathrm{Cl}$ value ' $\mathrm{O}$ ' represents the 'no communality' pole while '100' stands for 'full communality'. For a negative phrase a value of ' 0 ', that originally expressed 'full communality' was changed into '100' so that in all phrases '100' stands for 'full communality'. The following example provides an additional explanation (Box 2).

Box 2. Example of Communality Index (Cl)

\section{Communality Index (CI)}

The index refers to $0-100$ scale in pro-communality phrased questions. It is reversed when the question negates communality.

E.g. 1: Are you for full equality? This is a positively phrased question. The mean for it (variable X; for $\mathrm{N}$ responses) is 2.2 on a range extending from 1 (disagree) to 4 (fully agree). 2.2 is 1.2 above 1 (' $\mathbf{0}$ '). The $\mathbf{C l}$ is thus $(1.2 / 3) \times 100=40$.

E.g. 2: Are you for unequal pay? This variable $(Y)$ is negatively phrased. The scale is therefore reversed. 4 (agree) becomes ' 0 ' and ' 1 ' (disagree) is 100.2 .2 is now 1.8 below 4 (i.e., above ' $\mathbf{0}$ '). The $\mathbf{C l}$ is thus (1.8/3) $\mathrm{x}$ $100=60$.

\section{Inter-kibbutz and inter-age analysis}

The first part of the findings concerns the analysis of the differences between the two kibbutzim. Both have undergone changes, the first (1) is still classified as communal (shitufi) while the second (2) is defined as renewed, i.e., the most privatized form of the kibbutz.

In the analysis that we performed the $\mathrm{Cl}$ of kibbutz 1 was significantly higher than for kibbutz 2 on the equality set $[t(52)=4.83, p<0.01]$ and for the economy set $[t(53)=2.71$, $\mathrm{p}<0.01]$. There were no significant differences between the two kibbutzim for the basic values and consumption sets $[t(52)=1.45, p>0.05 ; t(52)=0.45, p>0.05$, respectively]. An analysis by age groups shows that the Cls of the older subjects are significantly higher than for the younger subjects only for the basic values set [t(51)=2.03, $p<0.05]$.

These findings are quite consistent with the observation that most of the younger generation do not follow their parents' ideology and tend to be more interested in material success. Only a small minority is still interested in the so called traditional kibbutz life-mode. These age differences have far-reaching implications for the kibbutz's future and practically on all the economic and social aspects of its life.

\section{Correlation analysis among the main question-sets}

The next statistical analysis is devoted to the correlation between the major sets of variables. As can be seen in Table 1, the correlation coefficient for all three paired sets are positive and, with the exception of two of the consumption sets (equality and business economy management), are significant. An additional analysis reveals that there are significant differences between the $\mathrm{Cl}$ results obtained from the different sets as described in Table $2[F(3,156)=14.66, p<0.001]$. For a more conclusive explanation of these results we suggest an in depth analysis of the individual variables of each set. 
Table 1. Basic sets - Pearson correlations

\begin{tabular}{|c|c|c|c|}
\hline \multicolumn{3}{|c|}{ Correlated Sets } & \multirow{2}{*}{$\frac{\text { Correlation Coefficients }}{0.497^{* *}}$} \\
\hline Equality & $x$ & Basic values & \\
\hline Equality & $x$ & Business economy & $0.414 * *$ \\
\hline Equality & $x$ & Consumption & Not significant \\
\hline Basic values & $x$ & Business economy & $0.399 * *$ \\
\hline Basic values & $x$ & Consumption & $0.323 *$ \\
\hline Consumption & $x$ & Business economy & Not significant \\
\hline
\end{tabular}

Significance: $*$ p 0.01-0.05** $p<0.001$

Table 2. Differences between the sets $(N=53)$

\begin{tabular}{|l|c|c|}
\hline \multicolumn{1}{|c|}{ Set } & Cl & Standard Deviation \\
\hline Basic values & 60.35 & 14.28 \\
Economy management & 50.74 & 17.80 \\
Equality & 44.06 & 23.66 \\
Consumption & 41.40 & 18.57 \\
\hline
\end{tabular}

\section{Attitudes toward the post-crisis changes}

In this section and those that follow, we present the findings of the individual variable analysis. Most kibbutzim had introduced some changes even before the crisis of the 1980s, but the changes were of a fairly marginal nature and did not violate the kibbutz basic principles that set it apart from the external milieu. The kibbutzim were thus still defined as 'fully collective'. The following discussion is concentrated on the post-1980s changes and our purpose was to obtain an impression about the members' attitudes towards the practice itself (Table 3).

Table 3. The Impact of the changes that were adopted by the Kibbutz since 1986 on the community and on individual members

\begin{tabular}{|l|c|}
\hline \multicolumn{1}{|c|}{ The effect on person or community } & ${\text { Mean for variable (scale: } 2-\mathbf{5})^{*}}^{*}$ \\
\hline For most the Kibbutz members & 4.18 \\
For future development prospects & 4.04 \\
For you personally & 4.18 \\
For the non-farm sector & 3.45 \\
For the farm sector & 2.57 \\
\hline
\end{tabular}

*Key: 2 - negative impact, 3 - no impact, 4 - slight impact, 5 - favourable impact

An analysis of variance confirmed the existence of a significant difference between the items $[F(4,116)=17.17$, sig<0.01]. Further repeated analysis confirmed that the last item was significantly low relative to the rest of the items in the group. The most outstanding finding of this set is the similarity between the respondent's perceived self-impact and the impacts perceived for the kibbutz' future development or, quite naturally, the impact of the changes on other kibbutz members. Significantly, however, a similar degree of an 
'egocentric' attitude does not apply to the existing economic sphere (farm and non-farm), for which the average scores tended to be lower, indicating less favourable attitudes to the introduced changes.

\section{Equality and related ideological values}

The analysis of variance test with these six repeated measures, confirmed that there are differences between the variables $[F(5,170)=6.10, p<0.001]$. According to subsequent simple effect tests we found that the first three items and the last three items clustered together into two distinct groups. This indicates that there are two subsets of values, but even the variables that obtained the highest $\mathrm{Cl}$ scores (Table 4) had only moderate $\mathrm{Cl}$. The low scores of the second sub-set suggest that full equality and communal unity are no longer part of the consensus. The relatively high $\mathrm{Cl}$ obtained for the differential pay option of the first sub-set means that there is somewhat higher support for equality than for inequality, but full equality is even less popular. The last item reveals that continuing communal control over real-estate is very popular; however, there is an almost unanimous desire for privatized dwelling.

Table 4. Equality and social or national values $(\mathrm{N}=35)$

\begin{tabular}{|l|c|c|}
\hline \multicolumn{1}{|c|}{ Variable } & Mean Cl & Standard Deviation (SD) \\
\hline Contribution to national and social welfare & 58.11 & 29.54 \\
General membership budget & 54.30 & 37.13 \\
Differential pay & 51.44 & 41.50 \\
Full equality pay & 40.01 & 41.86 \\
Separating business sector and community & 31.43 & 34.25 \\
Privatization of residential apartments & 27.61 & 53.69 \\
\hline
\end{tabular}

We also conducted a Pearson correlation analysis among these variables. The highest positive coefficients were obtained for the contrasting variables of full equality pay and differential pay $(0.607 ; \mathrm{p}<0.001)$. Residential privatization was also positively correlated with the same two contrasting variables at the $p<0.001$ level, and the correlations of business economy and community separation with the two contrasting payment variables were significant at the 0.05 level. The other variables were not significantly correlated.

Table 4 reveals that neither full equality - 'equal budget' - nor 'differential pay' are widely approved. These variables are, in fact, the two opposite poles of the full communal-full privatized spectrum. The low Cls for the residential and the community/business separation indicate the high popularity of these issues. Residential privatization is very popular but, as noted above, it has yet to be approved. The community/business separation issue has a somewhat higher $\mathrm{Cl}$ result, showing that it is less popular, yet the low support that it obtained is rather surprising in view of the far-reaching implications that the separation has for increasing the control of the kibbutz economy by non-kibbutz firms. This low $\mathrm{Cl}$ can be considered an obvious indication of the extent of decline of collective values.

National and social missions were originally basic tenets of all kibbutz movements. Their declining position is clearly evident in the lukewarm support they receive. This is an expression of the declining emphasis on socialist ideological values during recent years. 
One should not draw far-reaching conclusions from this relatively low $\mathrm{Cl}$, which may be interpreted as a 'backlash' response against the declining image of the kibbutz among many Israelis.

\section{Management and economic strategies}

The Cls for the kibbutz business management are presented in Table 5. The data show that the two extreme poles of the 'communality spectrum' have little support. The idea of transferring all management to any non-kibbutz body is clearly rejected. At the other pole, placing management solely in the hands of kibbutz members (or sharing it with other kibbutzim) was also unpopular. Not surprisingly, most of the respondents seem to have favoured a middle course.

Table 5. The members' position on various business management strategies ( $\mathrm{N}=30) \mathrm{Cl}$ (Means) and Standard Deviations (SD)

\begin{tabular}{|l|l|l|}
\hline \multicolumn{1}{|c|}{ Economic strategy } & Cl & SD \\
\hline Transfer management to external body without communal management & 97.78 & 12.17 \\
Manage the agricultural sector by non-kibbutz experts & 81.12 & 22.62 \\
Transfer management to non-kibbutz firms, but common directorate & 78.89 & 33.31 \\
Merge the industrial plants with non-kibbutz firms or private investors & 57.78 & 36.02 \\
Manage the branches by rotating kibbutz members & 56.68 & 36.26 \\
Manage the economy solely by the kibbutz but by qualified members & 48.90 & 35.82 \\
Establish profit centers for each of the kibbutz branches & 30.00 & 23.74 \\
Manage solely by the kibbutz or by sharing with other kibbutzim & 18.90 & 31.19 \\
\hline
\end{tabular}

An analysis of variance tests with these eight repeated measures, confirmed that there were differences between the variables of business management $[F(7,203)=26.74$, $p<0.001]$. According to subsequent simple effect tests we found that the eight items can be clustered into four sub-sets: (1) the first item, (2) the second and third, (3) the fourth, fifth and sixth and (4) the last two.

The fourth sub-set suggests that even though complete communal management is rejected, the strategy of transferring responsibility to profit centers is fairly popular. This apparent "inconsistency" can be seen as a vote, though lukewarm, in favour of decentralized management, in the hope that it will facilitate the supervision and the performance of the collective's industry.

The second subset points to the same, though not identical, tendency, but it can also be interpreted as favouring the retention, even though with some reservation, communal control. The hesitation to place management solely in members' hands may (3d sub-set) point to some disappointment with past management methods, but it may also reflect mistrust of specific kibbutz members. The last five variables, taken together, also reflect the rising preference for profit-maximization and the tendency to abandon the satisfier model that had prevailed before the 1980 s crisis. 


\section{Alternative uses of buildings and land}

We included in our questionnaire a set of questions that partly referred to the issue of privatizing unused residential buildings or premises and unused land resources (Table 6). In this case we felt that the way which we phrased the questions was not conducive for using the $\mathrm{Cl}$ ranking. We opted, therefore, for the more conventional tabulation method. Our assumption was that favoring re-use of abandoned structures by non-members indicated reduced communality values.

Table 6. Leasing unused and unproductive buildings or land - frequency and percentage (Total refers to valid responses only)

\begin{tabular}{|c|c|c|c|c|c|c|c|c|c|c|}
\hline & \multicolumn{2}{|c|}{ 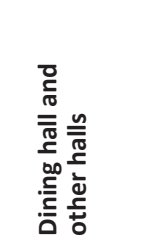 } & \multicolumn{2}{|c|}{ 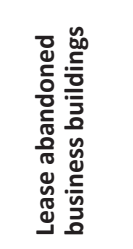 } & \multicolumn{2}{|c|}{ 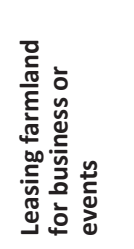 } & \multicolumn{2}{|c|}{  } & \multicolumn{2}{|c|}{ 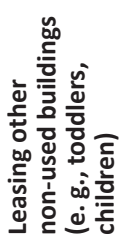 } \\
\hline & 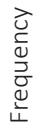 & 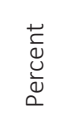 & 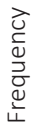 & 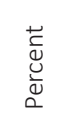 & 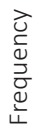 & 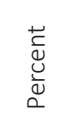 & 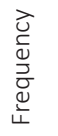 & 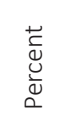 & 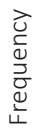 & 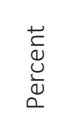 \\
\hline Sharing only & 3 & 5.5 & 3 & 5.5 & 12 & 21.8 & 15 & 27.3 & 10 & 18.2 \\
\hline Seasonal use only & 4 & 7.3 & 4 & 7.3 & 4 & 7.3 & 3 & 5.5 & 5 & 9.1 \\
\hline Special events & 13 & 23.6 & 5 & 9.1 & 6 & 10.9 & 8 & 14.5 & 2 & 3.6 \\
\hline No limit & 22 & 40.0 & 39 & 70.9 & 22 & 40.0 & 23 & 41.8 & 27 & 49.1 \\
\hline Total & 42 & 76.4 & 51 & 92.7 & 44 & 80.0 & 49 & 89.1 & 44 & 80.0 \\
\hline
\end{tabular}

Most of the members appear to favour the leasing (or re-using) of all the vacant properties with no reservation. The highest 'no limit' approval was for the leasing of abandoned business structures and the lowest approval rate was for the lease of the dining hall and the farmland. The dining hall was also the one which recorded the highest objection rate to any form of leasing.

\section{Privatization of consumption: Basic utilities}

The method of payment, if privatization is adopted, may differ according to additional personal considerations. Members having large families are likely to be against pricing by the number of users, while the aged, whose personal needs are unique, may be against payment by units of consumption because they tend to use larger amount than others, even though this pricing method guarantees optimal equity of unit costs. We took these options into consideration in phrasing the questionnaire (Table 7). 
Table 7. Privatization of basic utilities: Allocation and pricing criteria

\begin{tabular}{|lc|c|c|c|c|r|}
\hline \multicolumn{2}{|l|}{ Pricing method } & Opposed & Amount used & Family size & Seniority & Total \\
\hline Water & $\mathrm{N}$ & 13.0 & 34.0 & 6.0 & 1.0 & 54 \\
Telephones & $\mathrm{N}$ & 24.1 & 63.0 & 11.1 & 1.9 & 100 \\
& $\%$ & 6.0 & 37.0 & 11.0 & 1.0 & 55 \\
\multirow{2}{*}{ Electricity } & $\mathrm{N}$ & 11.0 & 67.3 & 20.0 & 1.8 & 100 \\
& $\%$ & 12.0 & 35.0 & 11.0 & 2.0 & 55 \\
\hline
\end{tabular}

\section{Privatization of other consumption goods and services}

A selected number of services that were formerly provided, or fully paid for, by the community, are shown in Table 8. The list contains the most common services that the kibbutz traditionally provided, but two of them, profit centers for certain services, such as grocery shops, belong to the recent innovative changes. The laundry service is still communally provided in many settlements, even though it is not vital as before. Many 'kibbutzniks' own private washing machines and no longer wear the 'blue-colour' garments that were rotated among them in the old days, when manual labour was the norm.

Table 8. Consumption set ( $\mathrm{N}=43)$

\begin{tabular}{|l|c|c|}
\hline \multicolumn{1}{|c|}{ Variable } & Cl & SD \\
\hline Kibbutz has to share cost of public services & 59.69 & 32.17 \\
Establish profit centers for public services & 46.51 & 33.48 \\
Pay for breakfast & 41.86 & 39.90 \\
Pay for laundry & 34.11 & 36.72 \\
Kibbutz-owned shop or mini-market & 17.05 & 25.59 \\
\hline
\end{tabular}

The establishment of services as profit centers applies to specialized enrichment classes or special sport facilities that the kibbutz provides to children of adjacent settlements. The respondents are divided about this issue, as they are also divided on the breakfast issue. The disparity of opinion may be explained, at least partly, by the presence of both users and providers of services among the respondents, but we have no evidence to support this hypothesis. The explanation for the disparity on the breakfast issue may be that it is not as vital as it used to be, as most members prefer to have it at home.

The high $\mathrm{Cl}$ of the first variable and the very low $\mathrm{Cl}$ stand out (Table 8). Both variables clearly differ from the rest. These differences were confirmed by the analysis of variance test $[F(4,168)=10.87, p<0.001]$. This reflects the real difference between the first question, which does not refer to any specific service, and the other three that deal with specific subjects. The last question is also unique, but like the second one, it deals with an innovation that was almost un-heard of during the founders' era.

The low $\mathrm{Cl}$ for the provision of shop or mini-market is the only one that obtained an almost unanimous score. This indicates that members definitely want to widen their choice of consumption goods and are willing to pay for this comfort. This is partly the result of the increasing ageing population, who require special products. It also reflects the diversi- 
ty of demand by members and non-member residents or wage labourers. The main factor is, however, that the local shop minimizes the range of basic goods. An added advantage is that the price of the locally sold items is lower than elsewhere because members are not charged much above the purchasing price. Shopping facilities are now widely acceptable, in fact, even by the staunchest supporters of collectivity.

Overall, these findings indicate that there is no full consensus about any of the items. This is, most probably, a true manifestation of the perplexity that prevails among the kibbutz members. The widespread private ownership of consumer goods such as refrigerators, radios, television sets, computers and a variety of other devices contributes to the tendency to regard the private purchases of these items as natural. The 'accumulation' of such items was originally resented, but gradually became acceptable.

\section{Discussion and conclusions}

The analytical method used here (under the limitation of the sample size) enabled us to offer some new insights on the transformation process that the kibbutz settlement type is presently undergoing. To answer our main question on the inter-relationship between values and management practices, we correlated the basic value sets with those of the economic management sets. The two sets, except those of consumption, were significantly correlated but the consequent analysis of the single variables suggested that these findings are not as simple as they seem to emerge from macro-scale set analysis. This may be because the macro-scale is not sufficiently discriminating to explain the entire range of the inter-relationship between ideology and pragmatism. The finer scale analysis reveals that the kibbutz members do stick to basic communality values, but that this generalization does not always apply when the values are more specifically presented.

This tendency applies to the issue of budget allocation, to favouring the separation of business and community, to the privatization of housing, to the re-use of vacated buildings and less clearly, to the issue of mutual guarantees. It is tempting to conclude that the high communality scores for caring for the needy and mutual help may not be more than expressions of support for past principles and do not necessarily reflect true altruism.

The evident relations among the main sets of variables seem to be reasonable as all reflect personal values. On the other hand, the low levels of correlation between ideas about consumption and the other values merit consideration. It seems that the subjects relate to the question of consumption as separate of other set of values. The same idea is probably conveyed by the finding of a difference in the $\mathrm{Cl}$ of basic values and the opinions regarding consumption. Kibbutz members want to detach their personal needs from the communal principals, which are largely attached to community and economic issues. Such are the responses regarding the impact of the changes the kibbutzim have adopted. While the changes are thought to impact personal lives they are less perceived as impacting the productive sectors of the kibbutz. This distinction implies that our subjects have a pragmatic way of thinking, whereby the personal and the collective spheres are judged in different manners.

The diversity of opinions on ideological tenets is reflected in the attitude toward the consumption sector and the relation to privatization. The opposition to privatization of utilities can be interpreted as favouring the continuation of common possession in order 
to avoid personal responsibility for the use of common resources. As already noted above, the self-interest of the individual kibbutz member, is expected to disfavour privatization of utilities, because it transfers the cost of use to his/her own purse. The public interest, on the other hand, calls for avoiding the responsibility over their use in order to reduce wastage and avoid the temptation of exposing the community to a conflict between the individual member's interest and that of the collective (see Hardin 1968).

Favouring the continuation of the pre-1980s practice of communal responsibility for the consumption of utilities is, thus, a sign of ego-centric motivation while a pro-privatization stand may be motivated by altruism. We adopted this, apparently paradoxical assumption, when we assessed the member's stand on the privatization of water, electricity or line telephones. It is difficult to judge the motivation of the minority who opposed the privatization of these utilities. It is surprising that privatization of water, the most vital utility, has not met with even higher resistance. The reason for this is apparently that the rate for rural water consumption, including domestic use, is still subsidized and therefore relatively cheap. Overall, however, the results indicate that self-interest was not a main consideration and that the members' position regarding the system of pricing favoured equity, i.e., to pay by units of consumption.

The findings about alternative usage of buildings and land suggest that member's position was determined by considering each item according to its own specific functional merit. The 'classical' kibbutz was traditionally against letting-out its land or its other properties to non-kibbutz persons (except for certain activities serving its members). The fact that, with a single exception, more than half of the interviewees were in favour of abandoning this objection indicates that pragmatism has prevailed over ideology. However, there was still a small minority who clings to the old principle, while others have some reservations about it.

It is not surprising that abandoned and vacant buildings obtained, generally, greater unconditional consent for re-use, even by external entrepreneurs, than other properties, and that the public halls got the highest degree of conditional or total refusal. The latter attitude reflects the sentimental, cultural and social importance attached by many members to the dining hall, which was the central meeting place for both business and social purposes. It functions, in many cases, as the major such place in the kibbutz even at present, but even this 'residual' usage is declining.

The implication of these findings is that most of the responding members were not opposed to opening up the kibbutz to non-member people or firms. The former exclusiveness has been radically altered. The 'fence' has been lowered, even though not entirely removed.

The members' responses to questions dealing with business management reveal that they are genuinely concerned with keeping the community's control over its property. Most of the respondents are aware of the need to alter the management practices of the traditional communal kibbutz. They also realize that adjusting it to the increasingly competitive and complex economy cannot be achieved by following earlier practices or by relying on the members' adherence to abstract ideology or to good-will and self-discipline. On the other hand, they seem to cherish the old values and believe that they brought some sort of economical safety.

This is especially evident in the unanimous opposition to fully granting kibbutz management to non-kibbutz bodies. The $\mathrm{Cls}$ for the kibbutz business management clearly 
reflect a rejection of the idea of transferring all management to any non-kibbutz body. At the same time placing management solely in the hands of kibbutz members (or sharing it with other kibbutzim) was also unpopular. The respondents favour a middle course.

The prevailing pragmatic approach of the interviewees testifies to the declining force of ideology. It also shows that communality, unless there is a sufficient degree of personal freedom, is hard to practice effectively in a highly complex and diverse world. This does not mean that 'common property' has been totally rejected and that there is justification for a full separation between community and economy. Our argument is, rather, that under highly dynamic conditions, when innovations follow each other at an unprecedented pace, it is necessary to pursue the most advanced management practices that can effectively cope with the situation. Even so, some of the members, especially the aged, prefer to preserve the values of the old kibbutz, and apply them as much as possible to the changing conditions.

The decentralization tendency, exemplified by the overwhelming support of the branch 'profit-centers' idea, is an innovation that points to the adoption of a principle that assures communal survival under the changing economic conditions: the need to provide a more specific purpose to the communal system by allocating each of the economic sectors a clear responsibility. A definite purpose, along with clear rules and sanctions for their violation, are considered among the basic principles of adequate communal management (Ostrum 1990).

Our research has yielded findings that point to the weakening of the communal system. One that stands out is that a growing number of members no longer endorse the former planned tenet of full equality. However, unlike equity (fairness), which must be strictly applied by communal leaderships, equality is not considered as an essential requirement for the sustainability of collectives (Oakerson 1992).

A more serious indication that threatens the very existence of the planned communal system is that the principle of collective ownership of the means of production is being progressively challenged. We found that the $\mathrm{Cl}$ of two kibbutzim, a 'communal' and a 'renewed' kibbutz, did not differ in respect to basic values and consumption, which stand on the two extremes of the sets depicted in Table 2. However, the members of the two kibbutzim did differ on the account of economy management. It seems that the shift of beliefs is centered on this point. At present, kibbutz members mostly insist on communal ownership of their resources, but there are a few renewed kibbutzim that have already abandoning this principle altogether (except for farmland which is state land). If this trend becomes an accepted norm, it will undermine the very essence of the kibbutz. Most of the interviewed communal managers do not welcome this extreme prospect. Yet there is no guarantee that the future generation will be of the same mind.

The essence and characteristics of the kibbutz as an ideal type of a community have changed in the last three decades. Values of equality among members, self-labour, collective production and consumption were all relaxed. The transfer of communal services to the household domain, payment for contribution to the community that was voluntary in the past and halting rotation in management jobs are just a number of examples for the erosion of the former basic principles on which the kibbutz ideology was based. These outcomes of this research are to some degree complementing early ideas put forward by Palgi (2002) and Getz (2009). In addition, the outcomes suggest that kibbutz movement is gradually heading towards being a profit-maximizing society. Moreover, the erosion in 
the degree of communalism and cooperation, and the increasing clash between common interest and self-interest are expressions of declining solidarity.

The kibbutz, as other planned cooperative settlements in Israel and in other developed countries, is in search of a new identity (Sofer and Grossman 2007). The communal system, which supported the social and economic structure, could not survive the changing economic conditions and a changing political-economic environment without a major transformation. There are a number of paths along which each community, the kibbutz in our case, may progress. In due course these changes may be gradual for some kibbutzim, and relatively more abrupt for others. Nonetheless, they may express a process of community convergence, by which the distinction between the cooperative settlements in Israel will lessen. The difficulties embedded in the process include reduced or even total loss of communal support for the needy and growing inequality between and within settlements. But there are also opportunities in this restructuring process. It may create new economic communities, which can better cope than the former structure with on-going economic and social changes, and still assure some degree of communality.

\section{References}

Andelson R. V., 1991, Commons without Tragedy: The Congruence of Garrett Hardin and Henry George, [in:] Andelson R. V. (ed.), Commons without Tragedy, Protecting the Environment from Overpopulation - a New Approach, London, Shepheard-Walwyn, pp. 27-43.

Ben-Rafael E., 1997, Crisis and Transformation: The Kibbutz at Century's End, Albany, State University of New York Press.

Ben-Rafael E., 2003, Report on the Kibbutz, Public Committee on the Kibbutzim Subject, Jerusalem (Hebrew).

Beteille R., 1994, La Crise Rurale, Que sais-je? Paris, Presses Universitaires de France.

Bijaui S., 2005, The Emergence of Regionalism in the Kibbutz Movement: The Case of the 'Valleys' Circle, Horizons in Geography, 63, pp. 133-163 (Hebrew).

Blomley N., 2005, Remember Property? Progress in Human Geography, 29 (2), pp. 125-127.

Central Bureau of Statistics (CBS), 2013, Statistical Abstract of Israel 2013, Jerusalem.

Cohen A., 2006, Why the Kibbutzim Will Stop Issuing Stocks in the Stock Exchange, Haaretz, The Marker June 7, 56 (Hebrew).

Degani O., 2006, The Regional Council as an Alternative Supporting System for the Changing Kibbutz, Horizons in Geography, 66, pp. 134-153 (Hebrew).

Discussions Team, 1991, The Kibbutz at the Turn of the Century: Crisis, Change, Continuity, Ramat Efal, Yad Tabenkin, First 3 meetings (Hebrew).

Discussions Team, 1992, The Kibbutz at the Turn of the Century: Crisis, Change, Continuity, Ramat Efal, Yad Tabenkin, Meetings 4, 5, 6 (Hebrew).

Edelman M., Roe J., Patton D., 1999, Land Use Conflict: When City and Country Clash, Dayton, $\mathrm{OH}$ : Kettering Foundation.

Gal A., 2011, From "We" to "Me": The Ideological Roots of the Privatization of the Kibbutz, [in:] Palgi M., Reinharz S. (eds.), One Hundred Years of Kibbutz Life: A Century of Crises and Reinvention, New Brunswick, Transactions, pp. 33-46.

Getz S., 1998, Winds of Change, [in:] Leviatan U., Quarter J., Oliver H. (eds.), Crisis in the Israeli Kibbutz: Meeting the Challenge of Changing Times, Westport, Praeger, pp. 13-25. 
Getz S., 2009, Changes in the Kibbutz - 2008, Haifa Institute of the Research of the Kibbutz and the Cooperative Idea, University of Haifa (Hebrew).

Grossman D., Kark R., 2004, Common Pool Management: Implications for Israeli Settlements, Horizons in Geography, 60-61, pp. 99-107 (Hebrew).

Hardin G., 1968, The Tragedy of the Commons, Science, 162, pp. 1243-1248.

Helman A., 1994, Privatization and the Israeli Kibbutz Experience, Journal of Rural Cooperation, 22 (1-2), pp. 19-32.

Hogeland J., 2004, How Culture Drives Economic Behavior in Cooperatives, Journal of Rural Cooperation, 32 (1), pp. 19-36.

Kibbutz Industries Association (KIA) internet site: http://www.kia.co.il/infoeng/about.htm

Lapidot A., Applebaum L., Yehudai M., 2000, From Protection to Competition: The Kibbutz in a Changing Environment, Ramat Efal, Yad Tabenkin (Hebrew).

Lapidot A., Applebaum L., Yehudai M., 2006, The Kibbutz in a Changing Environment - Between Survival and Preservation, Horizons in Geography, 66, pp. 7-27 (Hebrew).

McCarthy J., 2005, Rural Geography: Multifunctional Rural Geographies - Reactionary or Radical? Progress in Human Geography, 29 (6), pp. 773-782.

Ministry of Agriculture, Rural Planning and Development Authority, 2011, Economic Report on the State of Agriculture and the Rural Sector 2010 (Hebrew).

Morin S. R., 1996, Common Property and Exchange in a Natural Resource Management System: A Case Study from Aceh Province, Indonesia, Unpublished Ph.D Dissertation, University of Kentucky.

Mort J. A., Brenner G., 2003, Our Hearts Invented a Place: Can Kibbutz Survive in Today's Israel? Ithaca, Cornell University Press.

Netting R. M., 1993, Smallholders, Householders; Farm Families and the Ecology of Intensive, Sustainable Agriculture, Stanford, Stanford University Press.

Oakerson R. J., 1992, Analyzing the Commons: A Framework, [in:] Bromley D. W. (ed.), Making the Commons Work: Theory, Practice, and Policy, San Francisco, Institute for Contemporary Studies, pp. 41-59.

Ostrum E., 1990, Governing the Commons: The Evolution of Institutions for Collective Actions, Cambridge, Cambridge University Press.

Ostrum E., 1999, Coping with Strategies of the Commons, Annual Review of Political Science, 2, pp. 493-535.

Oved Y., 1993, American Communes: The Historical Experience in Agricultural Cooperatives in Transition, [in:] Csaki C., Kislev Y. (eds.), Boulder, Westview Press, pp. 383-392.

Palgi M., Orchan E., 2005, Public Opinion Survey in the Kibbutzim in 2005, Haifa, Haifa University, Kibbutz Research Institute (Hebrew).

Pauker A., 2011, The Early Roots of a Later Crisis - The Kibbutz Crisis of the 1980s and Its Roots at the Time of the Establishment of the State of Israel, [in:] Palgi M., Reinharz S. (eds.), One Hundred Years of Kibbutz Life: A Century of Crises and Reinvention, Transactions, New Brunswick, pp. 19-32.

Pavin A., 2011, Crisis, Social Capital and Community Resilience, [in:] Palgi M., Reinharz S. (eds) One Hundred Years of Kibbutz Life: A Century of Crises and Reinvention, Transactions, New Brunswick, pp. 59-71.

Palgi M., 2002, Organizational Change and Ideology: The Case of the Kibbutz, International Review of Sociology, 12 (3), pp. 289-402. 
Palgi M., Reinharz S., 2001, The Kibbutz at One Hundred: A Century of Crises and Reinvention, [in:] Palgi M., Reinharz S. (eds.), One Hundred Years of Kibbutz Life: A Century of Crises and Reinvention, New Brunswick, Transactions, pp. 1-12.

Ravid S., 1994, Is the Kibbutz Undergoing a Value Change? Journal of Rural Cooperation, 22 (1-2), pp. 33-40.

Robinson G. M., 2004, Geographies of Agriculture: Globalisation, Restructuring and Sustainability, Harlow, Pearson.

Rosner M., Getz S., 1994, Towards a Theory of Changes in the Kibbutz, Journal of Rural Cooperation, 22 (1-2), pp. 41-61.

Rosolio D., 1999, Crises, Adjustments and Changes in the Kibbutz Movement, Tel-Aviv, Am Oved (Hebrew).

Runge F., 1992, Common Property and Collective Action in Economic Development, [in:] Bromley D. W. (ed.), Making the Commons Work: Theory, Practice, and Policy, San Francisco, Institute for Contemporary Studies, pp. 17-39.

Russell R., Hanneman R., Getz S., 2006, Demographic and Environmental Influences on the Diffusion of Change among the Israeli Kibbutzim, 1990-2001, Worker Participation: Current Research and Future Trends: Research in the Sociology of Work, 16, pp. 269-297.

Schwartz M., 1995, Unlimited Guarantees: History, Political Economy and the Crisis of Cooperative Agriculture in Israel, Beer Sheva, Ben Gurion University Press, (Hebrew).

Schwartz M., 1999, The Rise and Decline of the Israeli Moshav Cooperative: A Historical Overview, Journal of Rural Cooperation, 27 (2), pp. 129-166.

Sofer M., 2009. Twenty Years of Change in the Fijian Periphery: The Case of the Kadavu Island, Fiji, Singapore Journal of Tropical Geography, 30, pp. 343-357.

Sofer M., Applebaum L., 2006, The Rural Space in Israel in Search of Renewed Identity: The Case of the Moshav, Journal of Rural Studies, 22, pp. 323-336.

Sofer M., Applebaum L., 2009, The Emergence of Farmers-Entrepreneurs as Local Development Agents in the Rural Space of Israel, Rural Studies, 20, pp. 107-125.

Sofer M., Grossman D., 2007, The Kibbutz in Search of a New Identity, Analele Universitatii Spiru Haret, Seria Geografie, 10, pp. 103-114.

Stevenson G. G., 1991, Common Property Economics: A General Theory and Land Use Applications, Cambridge, Cambridge University Press.

Storm M., 2011. The Thai revolution: The Changes in Agriculture in the Kibbutzim and Moshavim of the Arava in the 1990s, [in:] Palgi M., Reinharz S. (eds.), One Hundred Years of Kibbutz Life: A Century of Crises and Reinvention, New Brunswick, Transactions, pp. 289-301.

Topel M., 2011, The Changing Composition of Kibbutz Elites, [in:] Palgi M., Reinharz S. (eds), One Hundred Years of Kibbutz Life: A Century of Crises and Reinvention, New Brunswick, Transactions, pp. 47-58.

Topel M., Ben-Rafael, E., 2006, Technocratic Leadership in the Kibbutz, Horizons in Geography, 66, pp. 28-43 (Hebrew).

Woods M., 2010, Rural, London, Routledge. 
http://rcin.org.pl 